\title{
Aquaporin 9, a promising predictor for the cytocidal effects of arsenic trioxide in acute promyelocytic leukemia cell lines and primary blasts
}

\author{
NORIYOSHI IRIYAMA $^{1 *}$, BO YUAN $^{2 *}$, YUTA YOSHINO $^{2}$, YOSHIHIRO HATTA $^{1}$, AKIRA HORIKOSHI $^{1}$, \\ SHIN AIZAWA ${ }^{3}$, JIN TAKEUCHI ${ }^{1}$ and HIROO TOYODA ${ }^{2}$

\begin{abstract}
${ }^{1}$ Department of Hematology and Rheumatology, Nihon University School of Medicine, Itabashi Hospital, Itabashi-ku, Tokyo 173-8610; ${ }^{2}$ Department of Clinical Molecular Genetics, School of Pharmacy, Tokyo University of Pharmacy and Life Sciences, Hachioji, Tokyo 192-0392; ${ }^{3}$ Department of Functional Morphology,

Nihon University School of Medicine, Itabashi Hospital, Itabashi-ku, Tokyo 173-8610, Japan
\end{abstract}

Received December 24, 2012; Accepted February 21, 2013

DOI: $10.3892 /$ or.2013.2388

\begin{abstract}
A close correlation between the cytocidal effects of arsenic trioxide (ATO) and aquaporin-9 (AQP9) expression levels has been proposed, yet detailed studies are still needed to confirm this association. Thus, in the present study, the correlation between the expression levels of AQP9 and sensitivity to ATO was investigated using two acute promyelocytic leukemia (APL) cell lines, NB4 and HT93A, as well as primary APL cells from newly diagnosed and relapsed APL patients. A substantially higher sensitivity to ATO-mediated induction of apoptosis was observed in the NB4 cells when compared to that in the HT93A cells. In addition, markedly higher expression levels of AQP9, as assessed using flow cytometry, along with more intracellular arsenic accumulation, were observed in the NB4 cells. More importantly, similar to APL cell lines, the trend of expression levels of AQP9 correlated closely with the differential sensitivity to ATO-mediated induction of apoptosis in primary APL cells. In contrast, no correlation was observed between ATO sensitivity associated with AQP9 expression levels and the expression profiles of cell surface markers as well as chromosomal alterations. These results provide direct evidence that the expression levels of AQP9, rather than other biomarkers such as cell surface markers and chromosomal alterations, correlate closely with the sensitivity to ATO in both APL cell lines and primary blasts. These findings suggest that the AQP9 expression status of APL
\end{abstract}

Correspondence to: Dr Bo Yuan, Department of Clinical Molecular Genetics, School of Pharmacy, Tokyo University of Pharmacy and Life Sciences, 1432-1 Horinouchi, Hachioji, Tokyo 192-0392, Japan

E-mail: yuanbo@toyaku.ac.jp

*Contributed equally

Key words: aquaporin 9, acute promyelocytic leukemia, arsenic trioxide, NB4, HT93A patients is a predictive marker for the successful outcome of ATO treatment, since AQP9 plays a pivotal role in various arsenite-mediated biological effects on normal and cancer cells. Moreover, flow cytometry may be a new convenient and valuable tool for analyzing the AQP9 status of APL patients compared to current methods such as western blotting.

\section{Introduction}

Acute promyelocytic leukemia (APL) is characterized by a balanced reciprocal translocation between chromosome 15 and 17, generating the PML/RAR $\alpha$ fusion gene, which is thought to play a central role in the initiation of leukemogenesis (1-3). Conventional therapy comprising all-trans retinoic acid (ATRA), alone or in combination with chemotherapy, has dramatically improved the clinical outcome of this disease $(4,5)$. Nevertheless, $\sim 30 \%$ of patients relapse and often become resistant to conventional therapy (5). In this regard, a new breakthrough arsenic-based regimen has been established as a result of successful clinical outcomes showing that $90 \%$ of relapsed patients have been remitted by treatment with arsenic trioxide (ATO) (6-8). These results have led to the exploration of potential treatment applications for other malignancies, including solid tumors $(9,10)$. In order to understand the mode of actions of ATO and provide an effective treatment protocol for individual APL patients, detailed studies concerning the pharmacokinetics of ATO in APL patients have been conducted $(7,11)$. In fact, we clarified the distribution of arsenic metabolites, not only in peripheral blood and cerebrospinal fluid, but also in bone marrow from APL patients who received consecutive administration of ATO (12-14). These findings concerning the pharmacokinetics of ATO in APL patients provide a new insight into the clinical applications of ATO, and may contribute to better therapeutic protocols (15).

It is quite logical to consider that intracellular arsenic accumulation (As[i]) is critical for the control of various biological functions, and that its levels are tightly associated with arsenic uptake and efflux (16-21). Of note, aquaporin 9 (AQP9), a member of the aquaporin superfamily, has been proposed to 
be responsible for arsenite transport (16,18-21). It was demonstrated that As[i] in the K562 chronic myeloid leukemia cell line, transfected with AQP9, was significantly higher than the level in untransfected K562 cells, resulting in increased ATO-induced cytotoxicity $(16,18)$. Moreover, a retrospective study demonstrated that the expression level of AQP9 was significantly higher in bone marrow aspirate samples from APL patients compared to other subtypes of acute myeloid leukemia (AML) (18). We recently demonstrated that AQP9 and multidrug resistance-associated protein 2 contributed to the differential sensitivity of primary human-derived normal cells to arsenite (20) using a unique in vitro primary cell culture system (22-24). These findings indicate that sensitivity to ATO correlates with the expression levels of AQP9 in leukemia cells as well as normal cells, suggesting a close relationship between the cytocidal effect of ATO and the expression levels of AQP9. However, direct evidence for this correlation in primary APL cells from newly diagnosed and relapsed APL patients who have never received ATO therapy has not yet been provided.

ATO exerts a dual effect on APL cells $(15,25)$. Under high concentrations ranging from 1 to $2 \mu \mathrm{M}$, ATO induces apoptosis mainly through activation of a mitochondrial-mediated intrinsic apoptotic pathway. While under low concentrations ranging from 0.1 to $0.5 \mu \mathrm{M}$ with a longer treatment period, ATO tends to promote differentiation of APL cells. In order to evaluate the clinical efficiency of ATO in APL patients, flow cytometric analysis has been routinely performed to assess the expression levels of cell surface markers related to differentiation status, such as CD11b, CD15 and CD34 (12,26,27). It is well known that CD13 and CD56 are positively associated with the poor prognosis of APL patients treated with ATRA and/ or chemotherapy (28-32). However, whether these biological markers are appropriate to predict the efficacy of ATO in APL patients without a medication history of ATO still remains unclear.

In the present study, we hypothesized that AQP9 is a promising candidate biomarker with which to predict the efficacy of ATO in APL patients prior to ATO-based treatment. Our results provide initial direct evidence that the expression level of AQP9, rather than other biomarkers, correlates closely with sensitivity to ATO in both APL cell lines and primary blasts. Our findings suggest that the AQP9 status of patients with APL may be predictive of the success of ATO treatment.

\section{Materials and methods}

Materials. ATO was purchased from Sigma (St. Louis, MO, USA) and dissolved in $1 \mathrm{M}$ sodium hydroxide solution, diluted with phosphate-buffered saline (PBS), sterilized by filtration $(0.22 \mu \mathrm{m})$, and stored as a stock solution. The Apoptosis Detection Kit I, including Annexin V-fluorescein isothiocyanate (FITC), propidium iodide (PI), and 10X Annexin V binding buffer [0.1 M HEPES/NaOH (pH 7.4), 1.4 M NaCl, $25 \mathrm{mM} \mathrm{CaCl}_{2}$ ], was purchased from Becton-Dickinson (San Jose, CA, USA). Rabbit anti-rat AQP9 antibody (primary antibody) and FITC-labeled goat anti-rabbit IgG (secondary antibody) were purchased from Alpha Diagnostic (San Antonio, TX, USA) and Kirkegaard and Perry Laboratories (Gaithersburg, MD, USA), respectively, and dissolved in PBS as a stock solution and stored at $4^{\circ} \mathrm{C}$ until use.
Cell cultures and treatment. Two APL (NB4, HT93A), a myeloid leukemia (HL-60), a chronic myeloid leukemia (K562), and a T-cell leukemia (Jurkat) cell line were studied. The cells were cultured in RPMI-1640 medium (Gibco-BRL, Rockville, MD, USA) supplemented with $10 \%$ heat-inactivated fetal bovine serum (FBS) (Gibco-BRL) and antibiotics [100 U/ml of penicillin and $100 \mu \mathrm{g} / \mathrm{ml}$ of streptomycin (Gibco-BRL)] at $37^{\circ} \mathrm{C}$ in a humidified atmosphere $\left(5 \% \mathrm{CO}_{2}\right.$ in air). Cells were cultured at a density of $<1 \times 10^{6}$ cells $/ \mathrm{ml}$.

Bone marrow aspirates and peripheral blood were obtained from 5 newly diagnosed APL patients and 1 relapsed APL patient, who had never received ATO therapy. Prior to clinical therapy, mononuclear cell fractions were isolated from freshly collected bone marrow aspirates or peripheral blood using Lymphoprep ${ }^{\mathrm{TM}}$ (Cosmo Bio Co., Ltd., Tokyo, Japan), and the cell fractions were then cryopreserved until use. Prior to conducting the experiment, aliquots of the APL cells were rapidly thawed at $37^{\circ} \mathrm{C}$, washed with RPMI-1640, and resuspended at $1 \times 10^{6}$ cells/ml in RPMI-1640 supplemented with $10 \%$ FBS. Cell viability was assessed by trypan blue exclusion assay to ensure that cells were $>80 \%$ viable before the experiment. A written informed consent was obtained from the study patients before cell collection, and the study was approved by the Internal Review Committee of Nihon University Itabashi Hospital, Tokyo, Japan.

Determination of apoptosis. Induction of apoptosis was analyzed using the Apoptosis Detection Kit I according to the manufacturer's instructions. Briefly, cells were washed twice with cold PBS and then resuspended in $1 \mathrm{X}$ Annexin V binding buffer. Cells were then double stained with Annexin V-FITC and PI for $15 \mathrm{~min}$ at room temperature in the dark, followed by analysis within $1 \mathrm{~h}$. Apoptotic cells were determined by flow cytometry (Cyto ACE-150) with a minimum acquisition of 10,000 events for NB4 and HT93A cells, and 2,000-5,000 events for APL cells prepared from patients. The ratio of the number of early apoptotic cells [Annexin $\mathrm{V}(+) \mathrm{PI}(-)]$ plus the late apoptotic cells [Annexin $\mathrm{V}(+) \mathrm{PI}(+)$ ] to the total cell number was consider as the total apoptotic cell percentage. Cells were considered viable if they lacked both Annexin V and PI staining.

Analysis of intracellular As[i]. After exposure to $0.5 \mu \mathrm{M}$ ATO for the indicated time periods, cells were harvested and counted to provide accurate viable cell numbers, which were used to normalize As[i]. After washing three times with PBS, the cells were pelleted by centrifugation and stored at $-20^{\circ} \mathrm{C}$ until analysis. After transfer to $15-\mathrm{ml}$ polypropylene centrifuge tubes, cell pellets were mixed with $\mathrm{HNO}_{3}(0.1 \mathrm{ml})$ at room temperature for $10 \mathrm{~min}$, and incubated at $80^{\circ} \mathrm{C}$ on a hot plate for $90 \mathrm{~min}$. The samples were diluted with Milli-Q water to $3 \mathrm{ml}$, followed by analysis using inductively coupled plasma mass spectrometry (ICP-MS) (ELAN ${ }^{\circledR}$ DRC-e; Perkin-Elmer SCIEX, Concord, ON, Canada) for total arsenic determination, as described previously (14).

Reverse transcription-polymerase chain reaction (RT-PCR) analysis for AQP9 $m R N A$ expression. Total RNA and complementary DNA were prepared as described previously (22). Total RNA was extracted from cells using an RNA 


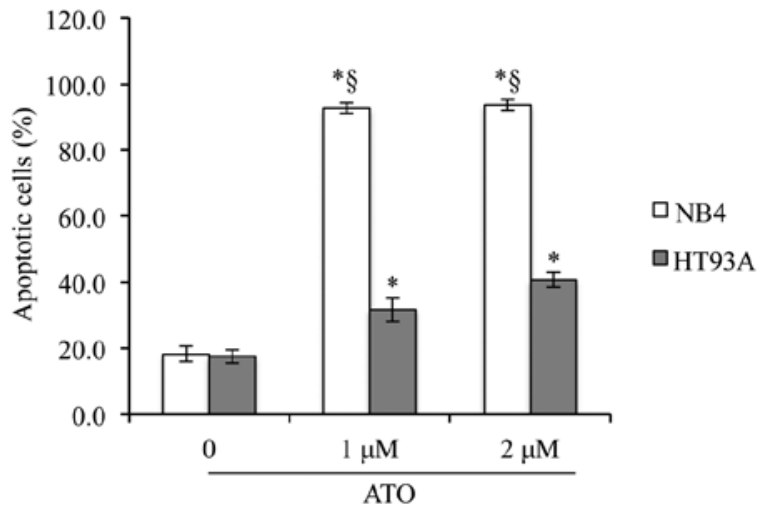

Figure 1. Induction of apoptosis in NB4 and HT93A cells by ATO. After treatment with ATO $(1$ or $2 \mu \mathrm{M})$ for $48 \mathrm{~h}$, apoptosis induction was determined using the Apoptosis Detection Kit I as described in Materials and methods. Significant differences were observed between control groups and ATO treatment groups ( $\mathrm{P}<0.01$ vs. control), and between NB4 and HT93A cells ( ${ }^{(} \mathrm{P}<0.05, \mathrm{NB} 4$ vs. HT93A).

extraction kit (Isogen). Complementary DNA was synthesized from $1 \mu \mathrm{g}$ of RNA using 100 pmol random hexamers and 100 units Moloney murine leukemia virus reverse transcriptase (Invitrogen, Carlsbad, CA, USA) in a total volume of $20 \mu \mathrm{l}$, according to the manufacturer's instructions. PCR was performed according to the method described previously (33), using a Takara Thermal Cycler MP (Takara Shuzo, Osaka, Japan). DNA primers for RT-PCR were purchased from SigmaAldrich (Tokyo, Japan): sense (5'-CTC AGT GTC ATC ATG TAG TG-3') and antisense primer (5'-GAC TAT CGT CAA GAT GCC G-3') for AQP9 mRNA; sense primer (5'-CCT TCC TGG GCA TGG AGT CCT G-3') and antisense primer (5'-GGA GCA ATG ATC TTG ATC TTC-3') for $\beta$-actin mRNA. PCR was carried out at the indicated cycles for AQP9 mRNA ( $30 \mathrm{sec}$ at $94^{\circ} \mathrm{C}$ for denaturation, $30 \mathrm{sec}$ at $60^{\circ} \mathrm{C}$ for annealing and $40 \mathrm{sec}$ at $72^{\circ} \mathrm{C}$ for extension); and 21 cycles for $\beta$-actin mRNA ( $1 \mathrm{~min}$ at $94^{\circ} \mathrm{C}$ for denaturation, $1 \mathrm{~min}$ at $55^{\circ} \mathrm{C}$ for annealing and $1 \mathrm{~min}$ at $72^{\circ} \mathrm{C}$ for extension) using a Takara Thermal Cycler MP. PCR products and Ready-Load ${ }^{\mathrm{TM}}$ 100-bp DNA ladder marker were electrophoresed, respectively, on a 2.0\% UltraPure ${ }^{\mathrm{TM}}$ agarose gel (both from Invitrogen), and visualized by ethidium bromide staining, followed by viewing under UV Light Printgraph (ATTO Corp, Tokyo, Japan).

Expression profiles of AQP9 protein expression. After washing with PBS containing 2.5\% FBS and $0.5 \% \mathrm{NaN}_{3}$ (PBSF), APL cells from patients and non-stimulated cultured leukemia cell lines were stained with rabbit anti-rat AQP9 antibody at a concentration of $10 \mu \mathrm{g} / \mathrm{ml}$ for $30 \mathrm{~min}$ at $4^{\circ} \mathrm{C}$ in the dark. After washing three times with PBSF, the cells were further stained with FITC-labeled goat anti-rabbit antibody, followed by analysis using flow cytometry (Cyto ACE-150). The relative expression level of AQP9 was shown as mean fluorescence intensity (MFI) and was calculated by subtracting the mean fluorescence of the unstained cells from that of the stained cells, as previously described (34). The specificity of FITClabeled secondary antibody for AQP9 analysis was confirmed based on no apparent observations of non-specific immunostaining by omitting the primary antibody.

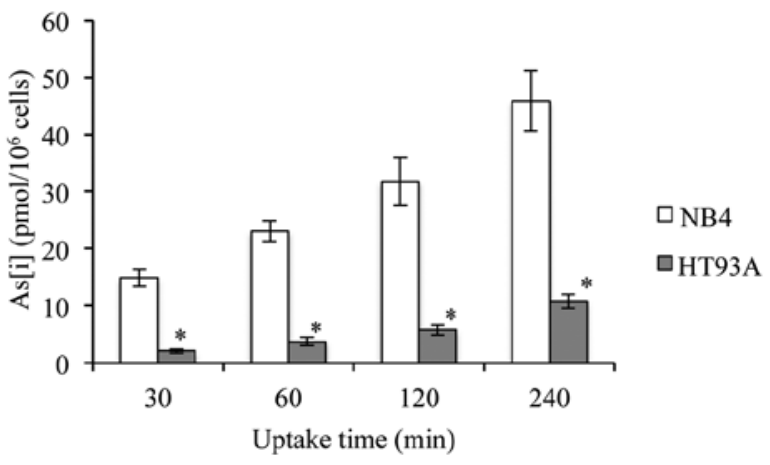

Figure 2. As[i] in NB4 and HT93A cells. The cell lines were treated with $0.5 \mu \mathrm{M}$ of ATO for $30,60,120$ and $240 \mathrm{~min}$, followed by the assessment of As[i] using ICP-MS. Significant differences were observed between the NB4 and HT93A cells $\left({ }^{*} \mathrm{P}<0.01, \mathrm{NB} 4\right.$ vs. HT93A).

Flow cytometric immunophenotypic analysis of APL cells from patients and NB4 and HT93A cell lines. A flow cytometric immunophenotypic analysis of the expression levels of CD11b, CD13, CD15, CD34 and CD56 in APL cells from patients and unstimulated cultured NB4 and HT93A cells was routinely conducted at Bio Medical Laboratories (BML, Tokyo, Japan).

Cytogenetic studies. Metaphase chromosomes were prepared and G-banded using trypsin and Giemsa (GTG) on bone marrow cell after a 48-h unstimulated culture. Twenty metaphases were counted and analyzed routinely according to International System for Human Cytogenetic Nomenclature (ISCN 2005) at our hospital.

Statistical analysis. Experiments were independently repeated three times, and the results are shown as means \pm standard deviation (SD) of three assays. A two-tailed, paired Student's t-test was applied, and a P-value $<0.05$ was considered to indicate a statistically significant result. The correlation in two factors was evaluated with Pearson product-moment correlation coefficient.

\section{Results}

Induction of apoptosis in the NB4 and HT93A cells by ATO. After treatment with ATO $(1$ or $2 \mu \mathrm{M})$ for $48 \mathrm{~h}$, a significant induction in apoptosis was observed in both NB4 and HT93A cells (Fig. 1). Furthermore, after treatment with $1 \mu \mathrm{M}$ ATO, a much higher percentage ( $\sim 90 \%)$ of apoptotic cells was observed in the NB4 cells when compared with the apoptotic rate of $\sim 30 \%$ cells in the HT93A cells (Fig. 1). These results indicate that NB4 cells are more sensitive to the apoptotic activity of ATO as compared to HT93A cells.

As[i] in NB4 and HT93A cells. After exposure to $0.5 \mu \mathrm{M}$ ATO for 30, 60, 120 and $240 \mathrm{~min}$, As[i] was measured by ICP-MS. As shown in Fig. 2, the levels of As[i] increased with time in both cell lines. Furthermore, the levels of As[i] were 4-7 times higher in the NB4 cells when compared to levels in the HT93A cells. Furthermore, the levels of As[i] in both untreated cell lines were less than the detection threshold (data not shown). 


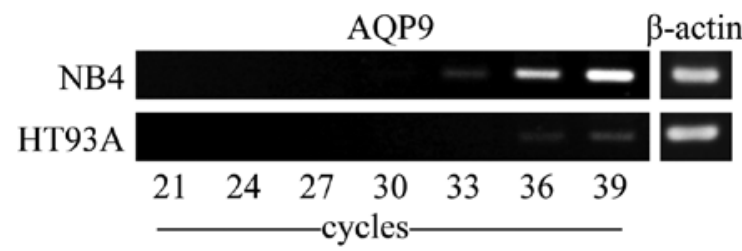

Figure 3. Expression profiles of AQP9 mRNA in NB4 and HT93A cells. The expression profiles of AQP9 mRNA were analyzed by RT-PCR, followed by an agarose gel electrophoresis as described in Materials and methods Experiments were carried out in three independent experiments, and representative electrophoretic profiles are shown.

Expression profiles of AQP9 $\mathrm{mRNA}$ in NB4 and HT93A cells. The expression profile of AQP9 mRNA was analyzed by RT-PCR. PCR was carried out for 21, 24, 27, 30, 33, 36 and 39 cycles, and the respective PCR products were harvested and subjected to agarose gel electrophoresis analysis. In NB4 cells, the expression of AQP9 mRNA was observed at a low but measurable level at cycle 33, and increased quickly and linearly with the amplification (Fig. 3). In contrast, only a measurable level of AQP9 was observed in the HT93A cells at cycle 39, indicating much higher expression levels of AQP9 mRNA in NB4 cells when compared with levels in the HT93A cells (Fig. 3).

Expression profiles of AQP9 protein in NB4 and HT93A and other leukemia cell lines. The expression levels of AQP9 protein in NB4 and HT93A cells were assessed using flow cytometry. Consistent with the expression level of AQP9 mRNA (Fig. 3), a much higher expression level of its protein was also observed in the NB4 cells when compared to the level in the HT93A cells (Fig. 4). Furthermore, the expression level of AQP9 was investigated in other leukemia cell lines, such as K562, Jurkat and HL-60. The rank order for the expression levels of AQP9 protein was NB4 > K562 > Jurkat > HL-60 > HT93A (Fig. 4), a result which is similar to previous experimental results determined by western blotting (18). Furthermore, the expression levels of AQP9 in primary APL cells from patients were evaluated as described above and are summarized in Table I.

Correlation of AQP9 expression with ATO sensitivity. The expression levels of AQP9 protein in NB4, HT93A and primary APL cells from patients $(\mathrm{Pt})$ showed the following trend: NB4 $>$ Pt6 $>$ Pt $1>$ Pt $2>$ Pt3 $>$ Pt4 $>$ Pt5 $>$ HT93A (Table I). Furthermore, the cytocidal effects of ATO on these cells were evaluated after treatment with $1 \mu \mathrm{M}$ ATO for $48 \mathrm{~h}$. As expected, the expression levels of AQP9 were found to be positively correlated with ATO-induced cytotoxicity not only in the APL cell lines but also in the primary APL cells from patients ( $\mathrm{P}=0.0049)$ (Fig. 5).

Immunophenotypic analysis of NB4 and HT93A cells and APL patient-derived cells. As summarized in Table I, NB4 cells demonstrated $\mathrm{CD} 11 \mathrm{~b}^{+} \mathrm{CD} 15^{+}$, whereas HT93A cells showed $\mathrm{CD}_{11 \mathrm{~b}^{-}}$and the number of $\mathrm{CD} 15^{+}$cells was as low as 24.3\%. Moreover, HT93A cells exhibited an expression level of CD34 as high as $88.1 \%$; however, NB4 cells were CD34, indicating the high differentiation degree of NB4 cells when compared to HT93A. A diverse range of expression profiles of CD11b, CD13, CD15, CD34 and CD56 was observed in the primary blasts from individual patients; however, unlike the strong correlations between AQP9 expression levels and ATO sensitivity, no correlation was observed between the expression profiles of these cell surface markers and ATO sensitivity. Apart from $\mathrm{t}(15 ; 17)$, other additional chromosomal changes were also identified in individual patients, as shown in Table I.

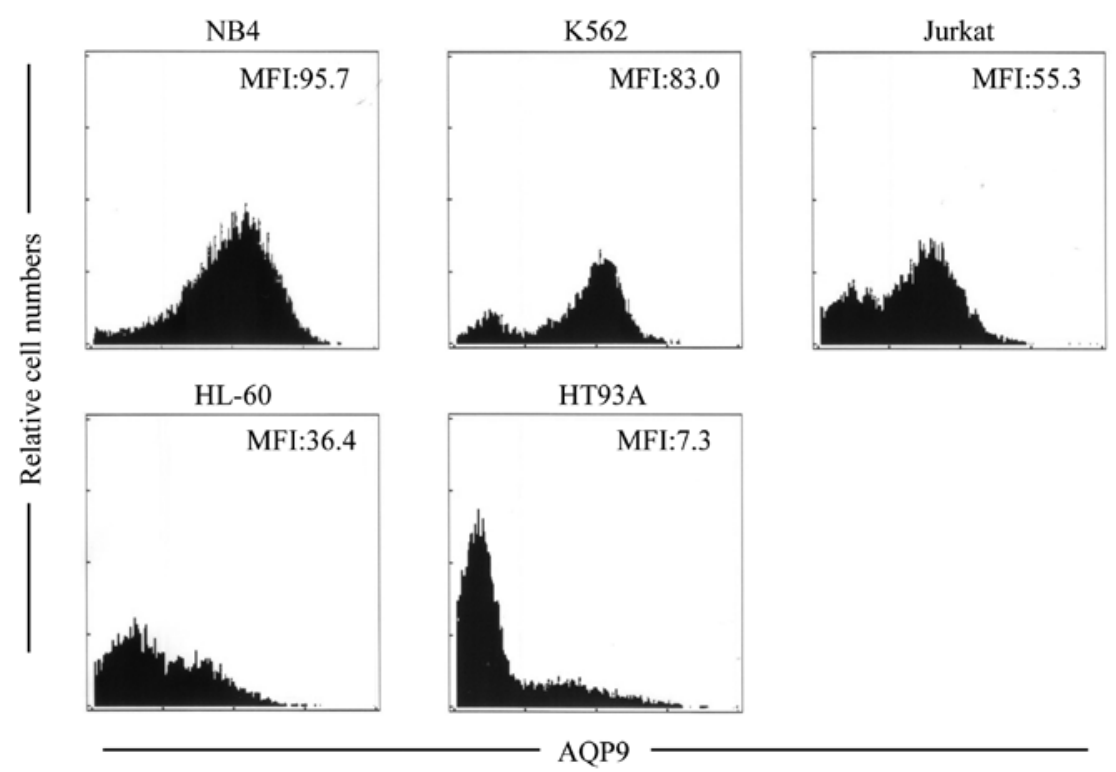

Figure 4. Expression profiles of AQP9 protein in leukemia cell lines. The expression levels of AQP9 protein in the NB4, K562, Jurkat, HL-60 and HT93A cells were assessed using flow cytometry as described in Materials and methods. The relative expression level of AQP9 is shown as the mean fluorescence intensity (MFI) and was calculated by subtracting the mean fluorescence of unstained cells from that of the stained cells, as previously described (34). Three independent experiments were carried out, and representative histogram profiles are shown. 
Table I. Characteristics of the NB4 and HT93A cells and APL patient-derived cells.

\begin{tabular}{lccccrrc}
\hline Samples & $\begin{array}{c}\text { AQP9 } \\
(\mathrm{MFI})\end{array}$ & $\begin{array}{c}\text { CD11b } \\
(\%)\end{array}$ & $\begin{array}{c}\text { CD13 } \\
(\%)\end{array}$ & $\begin{array}{c}\text { CD15 } \\
(\%)\end{array}$ & $\begin{array}{c}\text { CD34 } \\
(\%)\end{array}$ & $\begin{array}{c}\text { CD56 } \\
(\%)\end{array}$ & $\begin{array}{c}\text { Additive } \\
\text { chromosome }\end{array}$ \\
\hline NB4 & 95.7 & 48.2 & 97.8 & 61.7 & 0.5 & 8.2 & $\begin{array}{c}\text { Complex } \\
\text { HT93A }\end{array}$ \\
Patient 1 & 5.3 & 1.2 & 6.4 & 24.3 & 88.1 & 99.5 & $\mathrm{t}(1 ; 21)(\mathrm{q} 25 ; \mathrm{p} 13)$ \\
Patient 2 & 48.6 & 0.5 & 12.7 & 65.2 & 0.1 & 0.1 & Add(11)q(25) \\
Patient 3 & 39.5 & 0.5 & 42.8 & 52.7 & 0.1 & 0.6 & $(-)$ \\
Patient 4 & 36.9 & 0.3 & 43.1 & 19.9 & 0.1 & 1.8 & $(-)$ \\
Patient 5 & 33.1 & 1.9 & 90.0 & 13.0 & 0.3 & 0.1 & $(-)$ \\
Patient 6 & 94.3 & 23.7 & 97.5 & 78.8 & 8.2 & 86.2 & $-10,-12$ \\
\hline
\end{tabular}

A flow cytometric immunophenotypic analysis of the expression levels of CD11b, CD13, CD15, CD34 and CD56 in NB4, HT93A and primary APL cells from patients was routinely conducted at Bio Medical Laboratories (BML, Tokyo, Japan). A specific antigen was considered positive when $>20 \%$ of tested cells were stained compared to negative control. Cytogenetic studies were carried out according to International System for Human Cytogenetic Nomenclature (ISCN 2005). MFI, mean fluorescence intensity; APL, acute promyelocytic leukemia; AQP9, aquaporin-9.

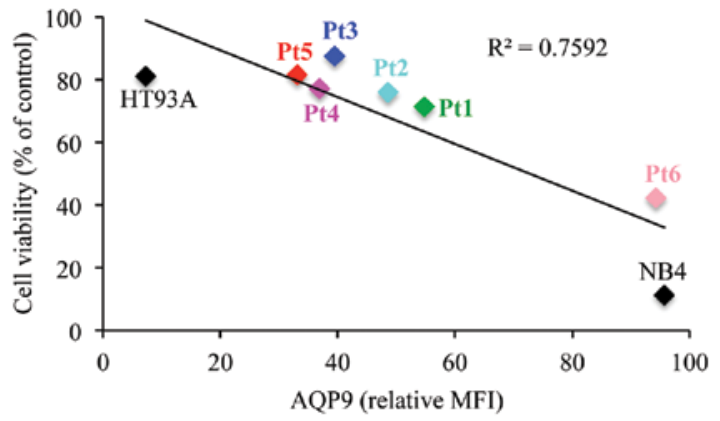

Figure 5. Correlation of AQP9 expression with ATO sensitivity. The expression level of AQP9 protein in primary APL cells from patients was investigated using flow cytometer as described in Fig. 4. After treatment with $1 \mu \mathrm{M}$ of ATO for $48 \mathrm{~h}$, apoptosis induction in these primary APL cells was determined by apoptosis detection kit I as described in Fig. 1. The relationship between the expression level of AQP9 and apoptosis-inducing activity of ATO was investigated among primary APL cells and APL cell lines, NB4 and HT93A. The Pearson product-moment correlation coefficient equals to 0.0049. Pt, patient; MFI, mean fluorescence intensity.

Again, no correlation was observed between chromosomal alterations and ATO sensitivity associated with AQP9 expression level.

\section{Discussion}

The present study clarified that relatively high concentrations of ATO (1 to $2 \mu \mathrm{M})$ triggered the induction of apoptosis in APL cell lines, NB4 and HT93A, as previously demonstrated by other researchers $(26,27,35,36)$. Furthermore, a substantially higher sensitivity to the apoptotic activity of ATO, along with more As[i], was observed in NB4 cells when compared to these values in HT93A cells. These results suggest that the sensitivity to ATO correlates closely with As[i].

Substantially high expression levels of AQP9 have been observed in NB4 cells, which results in high sensitivity to ATO (18). In agreement with this previous finding, we found markedly higher expression levels of AQP9 in NB4 cells when compared to levels in HT93A cells. It is noteworthy that in the present study, flow cytometry was used to investigate the expression profiles of AQP9 in leukemia cells, whereas PCR and/or western blotting have been used in the past. In fact, we recently applied this technique successfully to demonstrate time- and dose-dependent increases in the expression of AQP9 induced by ATRA in HT93A cells (37), similar to the phenomena observed in NB4 and HL-60 cells $(18,21)$. Moreover, flow cytometric analysis showed that the expression levels of AQP9 protein in all leukemia cells revealed the following trend: NB4 > K562 > Jurkat > HL-60 > HT93A, the results of which are in good agreement with previous experimental results determined by western blotting (18). Therefore, flow cytometry is a convenient and valuable tool for analyzing the AQP9 status of patients with APL, and the results of this analysis can be used to predict the response of patients with cancer to ATO.

Although a close relationship between the cytocidal effect of ATO and the expression level of AQP9 has been suggested $(15,18)$, there is no direct evidence to date concerning a correlation between the AQP9 expression level and the sensitivity to ATO based on research using primary APL cells. In this regard, our findings revealed a strong positive correlation between the AQP9 expression level and ATO sensitivity in primary APL cells from 6 patients, as well as in NB4 and HT93A cells. To the best of our knowledge, this is the first report to correlate the sensitivity to ATO with the AQP9 status of APL patients who have never received ATO therapy.

Furthermore, our results clearly demonstrated a relatively high degree of differentiation in the NB4 cells when compared to HT93A cells. Based on the results and the differences in the expression level of AQP9 and the sensitivity to ATO between the two cell lines, we suggest that there is a good correlation between the degree of differentiation associated with the expression level of AQP9 and ATO sensitivity. In other words, the cells with a relatively high degree of differentiation are more likely to express AQP9, which ultimately affects their sensitivity to ATO. However, a similar correlation was not observed in primary APL cells from patients. In 
addition, the expression levels of CD13 and CD56, known as prognostic factors for APL patient treated with ATRA and/ or chemotherapy (28-32), did not appear to be correlated with ATO sensitivity. Similarly, it appears that there is no correlation between chromosomal alterations and ATO sensitivity in all tested cells. Taken together, AQP9 plays a vital role in the differential sensitivity to ATO of APL cell lines and primary blasts. Therefore, monitoring both the expression level of AQP9 and the distribution of arsenic metabolites should be essential for better clinical outcome.

In conclusion, AQP9 is a vital clinical parameter with which to predict clinical achievement in APL patients prior to ATO-based treatment, although a larger scale study must be launched in order to draw a solid conclusion. Indeed, our hypothesis was strongly supported by a previous study (18), showing that APL patients expressed significantly higher AQP9 levels than patients with all other subtypes of AML among 80 cases of leukemia, yet the authors did not test the sensitivity of these primary APL cells to ATO. Furthermore, we recently demonstrated the contribution of AQP9 and multidrug resistance-associated protein 2 to the differential sensitivity of primary human-derived normal cells to arsenite (20). Given that these arsenic transporters play pivotal roles in various arsenite-mediated biological effects on normal and cancer cells, monitoring their expression levels has important implications for predicting not only clinical efficacy but also the risks of side effects in patients with cancer prior to ATO therapy.

\section{Acknowledgements}

This study was supported in part by grants from the Japan China Medical Association to B.Y. This study was also supported in part by grants from the Ministry of Education, Culture, Sports, Science and Technology and by the Promotion and Mutual Aid Corporation for Private Schools of Japan. The authors also thank Ms. Eiko Ishizuka for her technical assistance.

\section{References}

1. de Thé H, Chomienne C, Lanotte M, Degos L and Dejean A: The $t(15 ; 17)$ translocation of acute promyelocytic leukaemia fuses the retinoic acid receptor alpha gene to a novel transcribed locus. Nature 347: 558-561, 1990.

2. Goddard AD, Borrow J, Freemont PS and Solomon E: Characterization of a zinc finger gene disrupted by the $t(15 ; 17)$ in acute promyelocytic leukemia. Science 254: 1371-1374, 1991.

3. Tong JH, Dong S, Geng JP, Huang W, Wang ZY, Sun GL, Chen SJ, Chen Z, Larsen CJ and Berger R: Molecular rearrangements of the MYL gene in acute promyelocytic leukemia (APL, M3) define a breakpoint cluster region as well as some molecular variants. Oncogene 7: 311-316, 1992.

4. Burnett AK, Grimwade D, Solomon E, Wheatley K and Goldstone AH: Presenting white blood cell count and kinetics of molecular remission predict prognosis in acute promyelocytic leukemia treated with all-trans retinoic acid: result of the Randomized MRC Trial. Blood 93: 4131-4143, 1999.

5. Melnick A and Licht JD: Deconstructing a disease: RARalpha, its fusion partners, and their roles in the pathogenesis of acute promyelocytic leukemia. Blood 93: 3167-3215, 1999.

6. Cohen MH, Hirschfeld S, Flamm Honig S, Ibrahim A, Johnson JR, O'Leary JJ, White RM, Williams GA and Pazdur R: Drug approval summaries: arsenic trioxide, tamoxifen citrate, anastrazole, paclitaxel, bexarotene. Oncologist 6: 4-11, 2001.
7. Shen ZX, Chen GQ, Ni JH, Li XS, Xiong SM, Qiu QY, Zhu J, Tang W, Sun GL, Yang KQ, Chen Y, Zhou L, Fang ZW, Wang YT, Ma J, Zhang P, Zhang TD, Chen SJ, Chen Z and Wang ZY: Use of arsenic trioxide $\left(\mathrm{As}_{2} \mathrm{O}_{3}\right)$ in the treatment of acute promyelocytic leukemia (APL): II. Clinical efficacy and pharmacokinetics in relapsed patients. Blood 89: 3354-3360, 1997.

8. Soignet SL, Maslak P, Wang ZG, Jhanwar S, Calleja E, Dardashti LJ, Corso D, DeBlasio A, Gabrilove J, Scheinberg DA, Pandolfi PP and Warrell RP Jr: Complete remission after treatment of acute promyelocytic leukemia with arsenic trioxide. N Engl J Med 339: 1341-1348, 1998.

9. Dilda PJ and Hogg PJ: Arsenical-based cancer drugs. Cancer Treat Rev 33: 542-564, 2007.

10. Litzow MR: Arsenic trioxide. Expert Opin Pharmacother 9: 1773-1785, 2008.

11. Fujisawa S, Ohno R, Shigeno K, Sahara N, Nakamura S, Naito K, Kobayashi M, Shinjo K, Takeshita A, Suzuki Y, Hashimoto H, Kinoshita K, Shimoya M, Kaise T and Ohnishi K: Pharmacokinetics of arsenic species in Japanese patients with relapsed or refractory acute promyelocytic leukemia treated with arsenic trioxide. Cancer Chemother Pharmacol 59: 485-493, 2007.

12. Iriyama N, Yoshino Y, Yuan B, Horikoshi A, Hirabayashi Y, Hatta Y, Toyoda $\mathrm{H}$ and Takeuchi J: Speciation of arsenic trioxide metabolites in peripheral blood and bone marrow from an acute promyelocytic leukemia patient. J Hematol Oncol 5: 1-11, 2012.

13. Kiguchi T, Yoshino Y, Yuan B, Yoshizawa S, Kitahara T, Akahane D, Gotoh M, Kaise T, Toyoda H and Ohyashiki K: Speciation of arsenic trioxide penetrates into cerebrospinal fluid in patients with acute promyelocytic leukemia. Leuk Res 34: 403-405, 2010.

14. Yoshino Y, Yuan B, Miyashita SI, Iriyama N, Horikoshi A, Shikino O, Toyoda $\mathrm{H}$ and Kaise T: Speciation of arsenic trioxide metabolites in blood cells and plasma of a patient with acute promyelocytic leukemia. Anal Bioanal Chem 393: 689-697, 2009.

15. Yuan B, Yoshino Y, Kaise T and Toyoda $\mathrm{H}$ : Application of arsenic trioxide therapy for patients with leukaemia. In: Biological Chemistry of As, Sb and Bi. Sun HZ (ed). John Wiley and Sons, Ltd., New York, pp263-292, 2011.

16. Bhattacharjee H, Carbrey J, Rosen BP and Mukhopadhyay R: Drug uptake and pharmacological modulation of drug sensitivity in leukemia by AQP9. Biochem Biophys Res Commun 322: 836-841, 2004

17. Lee TC, Ho IC, Lu WJ and Huang JD: Enhanced expression of multidrug resistance-associated protein 2 and reduced expression of aquaglyceroporin 3 in an arsenic-resistant human cell line. J Biol Chem 281: 18401-18407, 2006.

18. Leung J, Pang A, Yuen WH, Kwong YL and Tse EW: Relationship of expression of aquaglyceroporin 9 with arsenic uptake and sensitivity in leukemia cells. Blood 109: 740-746, 2007.

19. Liu Z, Shen J, Carbrey JM, Mukhopadhyay R, Agre P and Rosen BP: Arsenite transport by mammalian aquaglyceroporins AQP7 and AQP9. Proc Natl Acad Sci USA 99: 6053-6058, 2002.

20. Yoshino Y, Yuan B, Kaise T, Takeichi M, Tanaka S, Hirano T, Kroetz DL and Toyoda H: Contribution of aquaporin 9 and multidrug resistance-associated protein 2 to differential sensitivity to arsenite between primary cultured chorion and amnion cells prepared from human fetal membranes. Toxicol Appl Pharmacol 257: 198-208, 2011.

21. Hu J, Liu YF, Wu CF, Xu F, Shen ZX, Zhu YM, Li JM, Tang W, Zhao WL, Wu W, Sun HP, Chen QS, Chen B, Zhou GB, Zelent A, Waxman S, Wang ZY, Chen SJ and Chen Z: Long-term efficacy and safety of all-trans retinoic acid/arsenic trioxide-based therapy in newly diagnosed acute promyelocytic leukemia. Proc Natl Acad Sci USA 106: 3342-3347, 2009.

22. Yuan B, Ohyama K, Bessho T and Toyoda H: Contribution of inducible nitric oxide synthase and cyclooxygenase-2 to apoptosis induction in smooth chorion trophoblast cells of human fetal membrane tissues. Biochem Biophys Res Commun 341: 822-827, 2006.

23. Yuan B, Ohyama K, Bessho T, Uchide $\mathrm{N}$ and Toyoda H: Imbalance between ROS production and elimination results in apoptosis induction in primary smooth chorion trophoblast cells prepared from human fetal membrane tissues. Life Sci 82: 623-630, 2008.

24. Yuan B, Ohyama K, Takeichi M and Toyoda H: Direct contribution of inducible nitric oxide synthase expression to apoptosis induction in primary smooth chorion trophoblast cells of human fetal membrane tissues. Int J Biochem Cell Biol 41: 1062-1069, 2009. 
25. Wang ZY and Chen Z: Acute promyelocytic leukemia: from highly fatal to highly curable. Blood 111: 2505-2515, 2008.

26. Chen GQ, Shi XG, Tang W, Xiong SM, Zhu J, Cai X, Han ZG, Ni JH, Shi GY, Jia PM, Liu MM, He KL, Niu C, Ma J, Zhang P, Zhang TD, Paul P, Naoe T, Kitamura K, Miller W, Waxman S, Wang ZY, de The $\mathrm{H}$, Chen SJ and Chen Z: Use of arsenic trioxide $\left(\mathrm{As}_{2} \mathrm{O}_{3}\right)$ in the treatment of acute promyelocytic leukemia (APL): I. $\mathrm{As}_{2} \mathrm{O}_{3}$ exerts dose-dependent dual effects on APL cells. Blood 89: 3345-3353, 1997.

27. Zhang TD, Chen GQ, Wang ZG, Wang ZY, Chen SJ and Chen Z: Arsenic trioxide, a therapeutic agent for APL. Oncogene 20: 7146-7153, 2001.

28. Di Bona E, Sartori R, Zambello R, Guercini N, Madeo D and Rodeghiero F: Prognostic significance of CD56 antigen expression in acute myeloid leukemia. Haematologica 87: 250-256, 2002

29. Ferrara F, Morabito F, Martino B, Specchia G, Liso V, Nobile F, Boccuni P, Di Noto R, Pane F, Annunziata M, Schiavone EM, De Simone M, Guglielmi C, Del Vecchio L and Lo Coco F: CD56 expression is an indicator of poor clinical outcome in patients with acute promyelocytic leukemia treated with simultaneous all-trans-retinoic acid and chemotherapy. J Clin Oncol 18: 1295-1300, 2000.

30. Montesinos P, Rayon C, Vellenga E, Brunet S, Gonzalez J, Gonzalez M, Holowiecka A, Esteve J, Bergua J, Gonzalez JD, Rivas C, Tormo M, Rubio V, Bueno J, Manso F, Milone G, de la Serna J, Perez I, Perez-Encinas M, Krsnik I, Ribera JM, Escoda L, Lowenberg B and Sanz MA: Clinical significance of CD56 expression in patients with acute promyelocytic leukemia treated with all-trans retinoic acid and anthracycline-based regimens. Blood 117: 1799-1805, 2011.

31. Schwarzinger I, Valent P, Koller U, Marosi C, Schneider B, Haas O, Knapp W, Lechner K and Bettelheim P: Prognostic significance of surface marker expression on blasts of patients with de novo acute myeloblastic leukemia. J Clin Oncol 8 423-430, 1990.
32. Vahdat L, Maslak P, Miller WH Jr, Eardley A, Heller G, Scheinberg DA and Warrell RP Jr: Early mortality and the retinoic acid syndrome in acute promyelocytic leukemia: impact of leukocytosis, low-dose chemotherapy, PMN/RAR-alpha isoform, and CD13 expression in patients treated with all-trans retinoic acid. Blood 84: 3843-3849, 1994.

33. Andus T, Targan SR, Deem R and Toyoda H: Measurement of tumor necrosis factor alpha mRNA in small numbers of cells by quantitative polymerase chain reaction. Reg Immunol 5: 11-17, 1993.

34. Ruan XZ, Varghese Z, Powis SH and Moorhead JF: Human mesangial cells express inducible macrophage scavenger receptor. Kidney Int 56: 440-451, 1999.

35. Cai X, Shen YL, Zhu Q, Jia PM, Yu Y, Zhou L, Huang Y, Zhang JW, Xiong SM, Chen SJ, Wang ZY, Chen Z and Chen GQ: Arsenic trioxide-induced apoptosis and differentiation are associated respectively with mitochondrial transmembrane potential collapse and retinoic acid signaling pathways in acute promyelocytic leukemia. Leukemia 14: 262-270, 2000.

36. Chen GQ, Zhu J, Shi XG, Ni JH, Zhong HJ, Si GY, Jin XL, Tang W, Li XS, Xong SM, Shen ZX, Sun GL, Ma J, Zhang P, Zhang TD, Gazin C, Naoe T, Chen SJ, Wang ZY and Chen Z: In vitro studies on cellular and molecular mechanisms of arsenic trioxide $\left(\mathrm{As}_{2} \mathrm{O}_{3}\right)$ in the treatment of acute promyelocytic leukemia: $\mathrm{As}_{2} \mathrm{O}_{3}$ induces NB4 cell apoptosis with downregulation of $\mathrm{Bcl}-2$ expression and modulation of PML-RAR alpha/PML proteins. Blood 88: 1052-1061, 1996.

37. Iriyama N, Yuan B, Hatta Y, Horikoshi A, Yoshino Y, Toyoda H, Aizawa $\mathrm{S}$ and Takeuchi J: Granulocyte colony-stimulating factor potentiates differentiation induction by all-trans retinoic acid and arsenic trioxide and enhances arsenic uptake in the acute promyelocytic leukemia cell line HT93A. Oncol Rep 28: 1875-1882, 2012. 